\title{
Ventilatory Ratio is a Valuable Prognostic Indicator in a Representative Observational Cohort of Patients with Acute Respiratory Distress Syndrome
}

\section{Emily R. Siegel}

UCSF: University of California San Francisco

Hanjing Zhuo

UCSF: University of California San Francisco

\section{Pratik Sinha}

Washington University In St Louis: Washington University in St Louis

Alexander I. Papolos

Medstar Washington Hospital Center

Siyuan A. Ni

Pulmonary Associates, Burlingame, CA

\section{Kathryn Vessel}

UCSF: University of California San Francisco

\section{Annika Belzer}

UCSF: University of California San Francisco

Emily B. Minus

UCSF: University of California San Francisco

\section{Carolyn S. Calfee}

UCSF: University of California San Francisco

\section{Michael A. Matthay}

UCSF: University of California San Francisco

Katherine DesPrez Wick ( $\nabla$ katherine.wick@ucsf.edu )

UCSF Medical Center https://orcid.org/0000-0001-9070-5490

\section{Research}

Keywords: Acute respiratory distress syndrome, pulmonary dead space, prognostic enrichment, pulmonary edema, ventilatory ratio

Posted Date: November 18th, 2021

DOI: https://doi.org/10.21203/rs.3.rs-1037916/v1 
License: (c) (i) This work is licensed under a Creative Commons Attribution 4.0 International License. Read Full License 


\section{Abstract}

\section{Background}

Estimating mortality risk is essential for prognostic enrichment. How various indices specific to respiratory compromise contribute to prognostication in patients with acute respiratory distress syndrome (ARDS) is not well-characterized in general clinical populations. The primary objective of this study was to identify variables specific to respiratory failure that add prognostic value to indicators of systemic illness severity. We tested the added benefit of respiratory variables in a representative observational cohort of patients with ARDS.

\section{Methods}

50 patients with ARDS were enrolled in a single-center, prospective, observational cohort. We tested the contribution of respiratory variables (oxygenation index, ventilatory ratio [VR], and the radiographic assessment of lung edema score) to logistic regression models of 28-day mortality adjusted for indicators of systemic illness severity (the Acute Physiology and Chronic Health Evaluation [APACHE] III score or severity of shock as measured by the number of vasopressors required at baseline). We also compared a model utilizing APACHE III with one including baseline number of vasopressors using the areas under their receiver operating curves.

\section{Results}

VR significantly improved model performance by likelihood ratio testing when added to APACHE III ( $p=$ $0.04)$ or vasopressor number at baseline $(p=0.01)$. Adjusted for APACHE III, each 0.5-unit change in VR was associated with an odds ratio for 28-day mortality of $1.78(95 \% \mathrm{Cl}=0.78-3.23)$. The number of vasopressors required at baseline had similar prognostic discrimination to the multi-component APACHE III. A model including the number of vasopressors and VR (area under the receiver operating curve [AUROC] 0.77, 95\% $\mathrm{Cl}$ 0.64-0.90) was comparable to a model including APACHE III and VR (AUROC 0.81 $(95 \% \mathrm{Cl} 0.68-0.93)$, $\mathrm{p}$ value for comparison $=0.58$.

\section{Conclusions}

In this observational cohort of patients with ARDS, the ventilatory ratio significantly improved discrimination for mortality when combined with indicators of severe systemic illness. Additionally, the number of vasopressors required at baseline and APACHE III had similar discrimination for mortality when combined with VR. The ventilatory ratio is easily obtained at the bedside and offers promise for both clinical prognostication and enriching clinical trial populations.

\section{Introduction}

Estimating mortality risk in the acute respiratory distress syndrome (ARDS) is a crucial component of clinical trial design because prognostic enrichment increases statistical power to detect an effect, a 
principle especially important in such a heterogeneous syndrome [1, 2]. Mortality in ARDS can be driven predominantly by a patient's underlying ARDS risk factor (such as sepsis), underlying comorbidities, or the severity of lung injury, in part measured by the degree of hypoxemia [3]. Respiratory variables alone do not fully capture mortality risk in ARDS given the heterogeneity of clinical risk factors and frequent concomitant multiorgan failure. Additionally, since respiratory failure is a substantial contributor to mortality in patients with ARDS [3], general severity of illness scores do not fully explain ARDS mortality risk.

Thus, metrics that are specific to both severity of critical illness and respiratory failure are necessary to best understand mortality in ARDS. For severity of illness, the Acute Physiology and Chronic Health Evaluation (APACHE) III score is highly associated with hospital mortality risk for critically ill adults [4]. APACHE III is not readily available in most clinical settings, however, and it is burdensome to calculate. The ventilatory ratio $(\mathrm{VR})$, representing the ratio of measured minute ventilation $\mathrm{x}$ measured arterial carbon dioxide tension $\left(\mathrm{PaCO}_{2}\right)$ / (ideal minute ventilation $\mathrm{x}$ ideal $\mathrm{PaCO}_{2}$ ), is an index of impaired ventilation that can be easily obtained at the bedside, correlates with pulmonary dead space, and is independently associated with an increased odds of hospital mortality even after adjusting for positive end-expiratory pressure, hypoxemia, and severity of illness [5]. A physiologic pulmonary dead space fraction of $<0.3$ and VR of 1 are considered normal, and higher values represent worse physiological derangements. A ventilatory ratio of at least 2 in ARDS ("high VR") has been shown to be associated with a higher risk of mortality [5]. Plasma biomarkers may also enhance prognostication in ARDS [6-8], and they have been integrated into parsimonious models that identify hypoinflammatory and hyperinflammatory ARDS phenotypes, which are associated with differential outcomes and treatment responses [9-13].

Many previous studies of mortality predictors in ARDS have utilized large clinical trial populations. Importantly, however, mortality from ARDS is higher in observational studies compared to randomized controlled trials (RCTs) [14], partially because observational studies often include patients who would be excluded from RCTs, such as those with severe comorbidities [14]. The aim of this research was to study the following questions in a cohort of critically ill patients with comorbidities and illness severity representative of the ARDS population outside of clinical trials: Which candidate variables specific to respiratory compromise will improve the performance of a logistic regression model describing 28-day mortality? Will the number of vasopressors required at baseline have comparable discriminatory power for mortality to APACHE III? Finally, will the hyperinflammatory and hypoinflammatory phenotypes with differential outcomes, previously identified in parsimonious models from large, randomized controlled trials, be present in a small, observational cohort?

\section{Methods}

\section{Study design and oversight}


This was a secondary analysis of a single-center prospective observational cohort study of subjects with ARDS who required endotracheal intubation and mechanical ventilation and were admitted to an intensive care unit in the Moffitt-Long Hospital (Parnassus Campus) at the University of California, San Francisco Medical Center. This study was approved by the institutional review board (\#17-21982).

\section{Human subjects: patient selection and informed consent}

Daily screening of the electronic medical record (EMR) from July 1, 2017 to March 12, 2019 was used to identify mechanically ventilated subjects who were endotracheally intubated and met the Berlin criteria for ARDS (including $\mathrm{PaO}_{2} / \mathrm{FiO}_{2}<300 \mathrm{mmHg}, \mathrm{PEEP} \geq 5 \mathrm{~cm} \mathrm{H}_{2} \mathrm{O}$ and bilateral infiltrates on chest radiography not fully explained by cardiogenic pulmonary edema) [15]. Patients were excluded if ARDS was present for 72 hours or longer prior to enrollment; they were younger than 18; had an expected survival of $<96$ hours; had a previous diagnosis of pulmonary hypertension; or were receiving mechanical circulatory support (extracorporeal membrane oxygenation, ventricular assist device, or intra-aortic balloon pump), on pulmonary vasodilators, or had been subject to externally-induced cardioplegia (such as in the setting of cardiopulmonary bypass) within 24 hours. Informed consent was obtained for all participants. If the patient was unable to provide consent, consent was obtained from a surrogate.

\section{Data Collection}

Clinical data were extracted from the EMR. Data collected at enrollment included patient demographics, primary and secondary risk factors for ARDS, comorbid conditions, and components of the APACHE III score. $\mathrm{PaO}_{2} / \mathrm{FiO}_{2}$, oxygenation index $\left(\mathrm{OI},\left[\mathrm{FiO}_{2} \times\right.\right.$ mean airway pressure $\left.\left.\times 100\right] / \mathrm{PaO}_{2}\right)$, ventilator parameters (plateau airway pressure, mean airway pressure, positive end-expiratory pressure [PEEP], tidal volume, respiratory system compliance, driving pressure), mode of ventilation, and pulmonary dead space fraction $\left(V_{D} / V_{T}\right)$ were also recorded at enrollment. $V_{D} / V_{T}$ was calculated from the Enghoff modification of the Bohr equation [16] utilizing simultaneous mixed-expired $\mathrm{CO}_{2}$ measured utilizing volumetric capnography (NICO Cardiopulmonary Management System, Novametrix, Wallingford, Connecticut) and arterial blood gas measurements. Two sequential calculations of $V_{D} / V_{T}$ were made using measurements with a five-minute interval, and these two values were then averaged to represent the patient's baseline pulmonary dead space fraction. Ventilatory ratio was calculated as (minute ventilation $[\mathrm{ml} / \mathrm{min}] \times \mathrm{PaCO}_{2}[\mathrm{mmHg}] /$ predicted body weight $\left.[\mathrm{kg}] \times 100 \times 37.5\right)$. Ventilator-free days (VFD) was calculated as days alive and free of mechanical ventilation to 28 days. ICU-free days was calculated as days alive and outside of the ICU to 28 days. For both outcomes, patients who die before 28 days were assigned zero.

\section{Biologic specimen collection, processing, and storage}

Blood samples were collected on the day of enrollment. Plasma obtained from two $10 \mathrm{~mL}$ EDTA anticoagulated blood samples was divided immediately after centrifugation into $0.5 \mathrm{~mL}$ and $1 \mathrm{~mL}$ aliquots and frozen at $-70^{\circ} \mathrm{C}$.

\section{Biomarker Measurements and Phenotype Assignment}


Angiopoietin-2 (Ang-2), receptor for advanced glycation end-products (RAGE), interleukin-6 (IL-6), interleukin-8 (IL-8), protein C, and soluble tumor necrosis factor receptor 1 (sTNFR-1) were measured in plasma samples obtained at study enrollment. Biomarkers were measured by ELISA (R\&D Systems, Minneapolis, MN, USA and Helena Laboratories, Beaumont, TX, USA). Biomarker measurements were made by a laboratory manager who was blinded to patient characteristics outside of inclusion/exclusion criteria. Hyperinflammatory and hypoinflammatory phenotype assignments were performed using previously validated model coefficients [9]. The probability cut-off was set at 0.5 , and the 3 -variable model was used given its higher specificity.

\section{Predictors and Endpoint}

The primary endpoint was 28-day mortality. Pre-specified candidate respiratory variables for the model were baseline $\mathrm{PaO}_{2} / \mathrm{FiO}_{2}$ ratio, oxygenation index, ventilatory ratio (VR, [Minute ventilation $\mathrm{x}$ $\left.\mathrm{PaCO}_{2}\right] /[$ Predicted body weight $x 100 \times 37.5]$ [ [17], and radiographic assessment of lung edema (RALE) score [18].

\section{Statistical Analyses}

Continuous variables are expressed as mean \pm SD or median (interquartile range [IQR]). Categorical variables are presented as count (percentage). Biomarker concentrations were $\log _{10}$ transformed to improve interpretability and better meet model assumptions.

For between-group comparisons, Fisher's exact test was used to compare categorical variables, two-sided unpaired t-test was used for normally distributed continuous variables, and the Mann-Whitney $U$ test was used for non-normally distributed continuous variables. Spearman correlation coefficients were used to describe all correlations and investigate collinearity between variables. Multivariable logistic regression utilizing manual step-wise backward selection and likelihood ratio testing for nested models was used for analyses of the association between candidate variables and 28-day mortality with appropriate model checking. Areas under receiver operating curves (ROC) were compared by the Delong test for non-nested models [19]. A two-sided $P$ value of $<0.05$ was considered significant. All analyses were performed using Stata SE 16.1 (StataCorp, College Station, TX).

\section{Results}

Of 322 patients screened for inclusion, 272 were excluded, and 50 patients were enrolled (Figure 1). Pneumonia was the most common primary ARDS etiology (46\%) (Table 1). The baseline APACHE III score was $107 \pm 30$, and $82 \%$ of the subjects had vasopressor-dependent shock. Many patients had major comorbid conditions such as cirrhosis, chronic lung disease, end stage renal disease, and heart failure. Most patients had at least one major comorbid condition. Baseline respiratory parameters are presented in Table 2. Most patients had a $\mathrm{PaO}_{2} / \mathrm{FiO}_{2}$ ratio less than $200 \mathrm{mmHg}$. Both $\mathrm{V}_{\mathrm{D}} / \mathrm{V}_{\mathrm{T}}(0.59 \pm 0.13)$ and $\mathrm{VR}$ (1.9 [1.6 - 2.3]) were elevated in this cohort. 28-day mortality was $56 \%$ (Table 3 ). High mortality accounted for a median of zero ventilator-free days (VFD) and ICU-free days. Median duration of 
mechanical ventilation among survivors was 9 days (IQR $4-20$ days). Median ICU duration among survivors was 11 days (IQR 7 - 21 days), and median length of hospitalization was 27 days (IQR $13-28$ days). 
Table 1

Baseline characteristics.

\section{Variable}

Age in years, median (IQR)

Female sex, n (\%)

Race, n (\%)

White

Black or African American

Asian

American Indian or Alaska Native

Native Hawaiian or Other Pacific Islander

Other

Hispanic or Latino Ethnicity

Primary Cause of ARDS

Pneumonia

Sepsis

Aspiration

Transfusion

Other

Primary and Secondary Cause of ARDS

Sepsis with pneumonia

Sepsis without pneumonia

Pneumonia without sepsis

Aspiration only
Results $(\mathrm{N}=50)$

$62(47-69)$

$23(46 \%)$

$21(42 \%)$

$6(12 \%)$

$11(22 \%)$

2 (4\%)

1 (2\%)

$9(18 \%)$

$9(18 \%)$

$23(46 \%)$

$12(24 \%)$

$9(18 \%)$

2 (4\%)

$4(8 \%)$

$14(28 \%)$

$13(26 \%)$

11 (22\%)

$8(16 \%)$

ARDS = Acute Respiratory Distress Syndrome

APACHE $=$ Acute Physiology and Chronic Health Evaluation

SOFA = Sequential Organ Failure Assessment

Immune suppression $=$ radiation, chemo, or $\geq 0.3 \mathrm{mg} / \mathrm{kg} /$ day prednisone or equivalent) within the past 6 months

+ Arrhythmia, coronary disease, or heart failure 


\begin{tabular}{|c|c|}
\hline Variable & Results $(\mathrm{N}=50)$ \\
\hline Other & $4(8 \%)$ \\
\hline \multicolumn{2}{|l|}{ Comorbidities } \\
\hline Cirrhosis & $8(16 \%)$ \\
\hline Chronic Lung Disease & $8(16 \%)$ \\
\hline End Stage Renal Disease & $3(6 \%)$ \\
\hline On dialysis & $2(4 \%)$ \\
\hline Cardiac Disease $^{+}$ & $14(28 \%)$ \\
\hline Heart Failure & $6(12 \%)$ \\
\hline Immune Suppression & $13(26 \%)$ \\
\hline Diabetes & $12(24 \%)$ \\
\hline Hypertension & $25(50 \%)$ \\
\hline Active cancer & $7(14 \%)$ \\
\hline Number of comorbidities, median (IQR) & $1(0-2)$ \\
\hline APACHE III score, mean \pm SD & $107 \pm 30$ \\
\hline Mean arterial pressure $(\mathrm{mmHg})$, median (IQR) & $72(65-80)$ \\
\hline On vasopressors at study enrollment, $\mathrm{n}(\%)$ & $41(82 \%)$ \\
\hline SOFA score, mean \pm SD & $12.4 \pm 5.0$ \\
\hline Non-pulmonary SOFA score, mean \pm SD & $9.2 \pm 4.9$ \\
\hline \multicolumn{2}{|l|}{ ARDS = Acute Respiratory Distress Syndrome } \\
\hline \multicolumn{2}{|c|}{ APACHE = Acute Physiology and Chronic Health Evaluation } \\
\hline \multicolumn{2}{|l|}{ SOFA = Sequential Organ Failure Assessment } \\
\hline \multicolumn{2}{|c|}{$\begin{array}{l}\text { Immune suppression = radiation, chemo, or } \geq 0.3 \mathrm{mg} / \mathrm{kg} / \text { day prednisone or equivalent) } \text { within the } \\
\text { past } 6 \text { months }\end{array}$} \\
\hline + Arrhythmia, coronary disease, or heart failure & \\
\hline
\end{tabular}


Table 2

Respiratory Parameters at Baseline.

\begin{tabular}{|c|c|}
\hline Variable & Mean \pm SD or Median (IQR) \\
\hline PEEP, $\mathrm{cmH}_{2} \mathrm{O}$ & $10(8-10)$ \\
\hline Plateau airway pressure, $\mathrm{cm} \mathrm{H}_{2} \mathrm{O}$ & $25.6 \pm 5.3$ \\
\hline Minute ventilation, Liter/min & $11.0 \pm 3.1$ \\
\hline Mean airway pressure, $\mathrm{mmHg}$ & $16.0 \pm 4.0$ \\
\hline Compliance, $\mathrm{mL} / \mathrm{cm} \mathrm{H}_{2} \mathrm{O}$ & $26.8(20.9-32.0)$ \\
\hline Driving pressure, $\mathrm{cm} \mathrm{H}_{2} \mathrm{O}$ & $15.8 \pm 4.9$ \\
\hline Tidal Volume, ml/kg PBW & $6.7(6.1-7.5)$ \\
\hline Total Respiratory Rate & $26 \pm 7$ \\
\hline $\mathrm{PaO}_{2}$ to $\mathrm{FiO}_{2}$ ratio, $\mathrm{mmHg}$ & $159 \pm 55$ \\
\hline Oxygenation index, $\mathrm{mmHg}$ & $11.3(7.3-13.9)$ \\
\hline Mean pulmonary dead space fraction $\left(V_{D} / V_{T}\right)$ & $0.59 \pm 0.13$ \\
\hline Ventilatory Ratio & $1.9(1.6-2.3)$ \\
\hline RALE score & $24.0 \pm 8.4$ \\
\hline \multicolumn{2}{|l|}{ Ventilation mode } \\
\hline Volume control & $42(84 \%)$ \\
\hline Pressure control & $5(10 \%)$ \\
\hline Pressure support & $2(4 \%)$ \\
\hline PC IRV & $1(2 \%)$ \\
\hline \multicolumn{2}{|l|}{ PEEP = Positive end-expiratory pressure } \\
\hline \multicolumn{2}{|l|}{$\mathrm{PBW}=$ predicted body weight } \\
\hline \multicolumn{2}{|c|}{ Oxygenation Index $=\left[\mathrm{FiO}_{2} \times\right.$ mean airway pressure $\left.x 100\right] / \mathrm{PaO}_{2}$} \\
\hline \multicolumn{2}{|c|}{ Ventilatory Ratio $=\left[\right.$ Minute ventilation $\left.\times \mathrm{PaCO}_{2}\right] /[$ Predicted body weight $\times 100 \times 37.5]$} \\
\hline RALE = radiographic assessment of lung edem & \\
\hline
\end{tabular}


Table 3

Clinical Outcomes.

\begin{tabular}{|ll|}
\hline Variable & Results \\
\hline Status at day 28, N (\%) & $7(14 \%)$ \\
\hline Home W/ UAB & $28(56 \%)$ \\
\hline Dead & $15(30 \%)$ \\
\hline Other & $9(18 \%)$ \\
\hline Still hospitalized & $5(10 \%)$ \\
\hline Discharged to SNF/acute rehab & $1(2 \%)$ \\
\hline Transferred to another hospital & $31(62 \%)$ \\
\hline Dead at Day 60 & $0(0-16)$ \\
\hline Ventilator-free days at day 28, median (IQR) & $9(4-20)$ \\
\hline Days on ventilator at day 28 among survivors, median (IQR) & $0(0-13)$ \\
\hline ICU-free days at day 28, median (IQR) & $11(7-21)$ \\
\hline ICU days at day 28 among survivors, median (IQR) & $27(13-28)$ \\
\hline Hospital days at day 28 among survivors, median (IQR) & \\
\hline UAB = unassisted breathing & \\
\hline SNF = skilled nursing facility & \\
\hline ICU = intensive care unit & \\
\hline
\end{tabular}

The APACHE III score and the non-pulmonary SOFA score were significantly higher among non-survivors as compared to survivors (Table 4). Non-survivors required a significantly greater number of vasopressors at baseline. VR was significantly higher among non-survivors, $p=0.01$ (Figure 2). Mortality among patients with high VR $(V R \geq 2)$ was $78 \%$ vs. $37 \%$ in the low VR group $(p=0.005)$. Among plasma biomarkers, IL-8 and STNFR-1 concentrations were significantly higher and protein C was significantly lower among non-survivors (Table 4). 
Table 4

Baseline Characteristics by Mortality at Day 28.

\begin{tabular}{|llll|}
\hline Variable & $\begin{array}{l}\text { Alive } \\
(\mathbf{N}=\mathbf{2 2})\end{array}$ & $\begin{array}{l}\text { Dead } \\
\mathbf{( N = 2 8 )}\end{array}$ & P-value \\
\hline Age & $59(44-69)$ & $63(51-70)$ & 0.35 \\
\hline Female sex, $\mathrm{( \% )}$ & $8(37 \%)$ & $15(54 \%)$ & 0.26 \\
\hline APACHE III, mean \pm SD & $90 \pm 32$ & $119 \pm 22$ & 0.0004 \\
\hline PaO2:FiO2, mean \pm SD & $171 \pm 50$ & $151 \pm 58$ & 0.20 \\
\hline Non-pulmonary SOFA, mean \pm SD & $6.9 \pm 4.2$ & $11.0 \pm 4.7$ & 0.003 \\
\hline Oxygenation index & $8.9(6.6-11.9)$ & $12.2(7.9-16.5)$ & 0.09 \\
\hline Vasopressor 24 h prior to enrollment & $19(86.4 \%)$ & $22(78.6 \%)$ & 0.48 \\
\hline Vasopressor number at baseline & $1(1-1)$ & $1(1-2)$ & 0.04 \\
\hline Pulmonary dead space fraction & $0.56 \pm 0.12$ & $0.61 \pm 0.14$ & 0.14 \\
\hline Minute ventilation, Liter/min & $9.77 \pm 2.80$ & $12.00 \pm 3.01$ & 0.01 \\
\hline Ventilatory Ratio & $1.67(1.47-1.97)$ & $2.24(1.81-2.54)$ & 0.002 \\
\hline RALE score & $23 \pm 9$ & $25 \pm 8$ & 0.27 \\
\hline APACHE = Acute Physiologic Assessment and Chronic Health Evaluation & \\
\hline SOFA = Sequential Organ Failure Assessment & & \\
\hline RALE = Radiographic Assessment of Lung Edema & & \\
\hline Ang = Angiopoietin & & & \\
\hline IL = Interleukin & & & \\
\hline sTNFR = soluble Tumor Necrosis Factor Receptor & & \\
\hline RAGE = Receptor for Advanced Glycation End-products & & \\
\hline
\end{tabular}

We first tested correlations among candidate variables to minimize collinearity within candidate logistic regression models. There was a strong negative correlation between $\mathrm{PaO}_{2} / \mathrm{FiO}_{2}$ ratio and $\mathrm{OI}(\rho=-0.91, \mathrm{p}<$ 0.0001). Moving forward, we included $\mathrm{Ol}$ as a prognostic indicator in candidate models instead of $\mathrm{PaO}_{2} / \mathrm{FiO}_{2}$ given the existing body of evidence that $\mathrm{OI}$ is an independent risk factor for mortality in adults with ARDS [20-22] and that $\mathrm{PaO}_{2} / \mathrm{FiO}_{2}$ ratio is not consistently associated with mortality [22-24]. Univariable logistic regression for each candidate variable, the full candidate logistic regression model, and the final model for 28-day mortality using physiological variables is depicted in Table 5. Using backward selection and likelihood ratio testing, we eliminated OI and the RALE score from the model. VR 
significantly improved the model of 28-day mortality as compared to a model including APACHE III alone $(p=0.04$ by likelihood ratio test). Adjusted for APACHE III, each 0.5 -unit change in VR was associated with OR for 28-day mortality of $1.78(95 \% \mathrm{Cl}=0.78-3.23)$. The model including APACHE III and VR had an area under the receiver operating curve (AUROC) of $0.81(95 \% \mathrm{Cl} 0.68-0.93)$.

Table 5

Candidate logistic regression models of 28-day mortality using physiologic variables.

\begin{tabular}{|c|c|c|c|}
\hline & Odds Ratio & 95\% Confidence Interval & P-value \\
\hline \multicolumn{4}{|c|}{ Individual Regression Models (Unadjusted) } \\
\hline APACHE III Score & 1.04 & $1.01-1.06$ & 0.002 \\
\hline Oxygenation Index & 1.10 & $0.97-1.23$ & 0.13 \\
\hline Ventilatory Ratio ${ }^{+}$ & 2.09 & $1.12-3.91$ & 0.02 \\
\hline RALE Score & 1.04 & $0.97-1.12$ & 0.27 \\
\hline \multicolumn{4}{|c|}{ Combined Candidate Model } \\
\hline APACHE III Score & 1.05 & $1.02-1.08$ & 0.003 \\
\hline Oxygenation Index & 0.93 & $0.79-1.09$ & 0.37 \\
\hline Ventilatory Ratio ${ }^{+}$ & 2.08 & $0.99-4.39$ & 0.05 \\
\hline RALE Score & 1.09 & $0.99-1.20$ & 0.09 \\
\hline \multicolumn{4}{|l|}{ Final model } \\
\hline Ventilatory Ratio ${ }^{+}$ & 1.78 & $0.78-3.23$ & 0.06 \\
\hline APACHE IIII & 1.03 & $1.01-1.05$ & 0.009 \\
\hline \multicolumn{4}{|c|}{ +Per 0.5 unit increase } \\
\hline \multicolumn{4}{|c|}{ APACHE = Acute Physiologic Assessment and Chronic Health Evaluation } \\
\hline \multicolumn{4}{|c|}{ RALE = Radiographic Assessment of Lung Edema } \\
\hline $\mathrm{IL}=$ interleukin & & & \\
\hline
\end{tabular}

Vasopressors are an indicator of a patient's severity of illness and risk for multisystem organ failure, and the number of vasopressors a patient is receiving is much easier to calculate than APACHE III in a clinical setting. Thus, we tested whether VR significantly improved a model of 28-day mortality when combined with the number of vasopressors a patient was receiving at baseline. Indeed, VR significantly improved model performance by likelihood ratio testing when added to vasopressor number at baseline $(p=0.01)$. We also compared the performance of a model including VR and APACHE III to the performance of a 
model including VR and vasopressor number. The model including vasopressor number and VR had an AUROC of $0.77(95 \% \mathrm{Cl} 0.64-0.90)$. This was comparable ( $p$-value for comparison $=0.58$ ) to the model of APACHE III with VR, which had an AUROC of 0.81 (95\% Cl $0.68-0.93)$.

Lastly, we tested whether ARDS phenotypes that have been identified in secondary analyses of randomized clinical trials and large, well-phenotyped observational cohorts are also present in a small observational cohort. These phenotypes can be accurately identified with a parsimonious classifier model consisting of three plasma biomarkers: IL-8, protein C, and bicarbonate [9]. We found similar proportions of patients were classified as hyperinflammatory (38\%) and hypoinflammatory $(62 \%)$ in our cohort as in prior work [9]. Mortality in the hyperinflammatory group was higher $(71 \%)$ than in the hypoinflammatory group (46\%), although this difference did not meet statistical significance $(p=0.11)$ (Table 6). Thus, even in this small observational cohort with high baseline mortality, ARDS sub-phenotypes with distinct clinical trajectories were readily identified. 
Table 6

Phenotype assignment by a value greater than 0.5 in 3-variable model (IL-8, Protein C and Lowest Bicarbonate).

\begin{tabular}{|c|c|c|c|}
\hline Variable & $\begin{array}{l}\text { Hyper-Inflammatory } \\
(\mathrm{N}=17)\end{array}$ & $\begin{array}{l}\text { Hypo-inflammatory } \\
(\mathrm{N}=28)\end{array}$ & P-value \\
\hline IL-8 & $217(143-407)$ & $41(28-77)$ & $<0.001$ \\
\hline Lowest bicarbonate & $17(13-21)$ & $23(19-27)$ & 0.001 \\
\hline Protein C & $40(20-46)$ & $83(70-95)$ & $<0.001$ \\
\hline \multicolumn{4}{|l|}{ Baseline Characteristics: } \\
\hline APACHE III, mean \pm SD & $128 \pm 19$ & $94 \pm 29$ & 0.0001 \\
\hline $\mathrm{PaO}_{2}: \mathrm{FiO}_{2}$, mean $\pm \mathrm{SD}$ & $155 \pm 66$ & $168 \pm 49$ & 0.46 \\
\hline RALE, mean \pm SD & $23 \pm 8$ & $24 \pm 8$ & 0.85 \\
\hline $\begin{array}{l}\text { Non-pulmonary SOFA, } \\
\text { mean } \pm \text { SD }\end{array}$ & $12.7 \pm 3.9$ & $6.7 \pm 3.6$ & $<0.001$ \\
\hline Ventilatory Ratio (IQR) & $2.01(1.84-2.32)$ & $1.67(1.46-1.24)$ & 0.04 \\
\hline Dead space fraction, mean \pm SD & $0.61 \pm 0.14$ & $0.57 \pm 0.14$ & 0.40 \\
\hline Oxygenation index (IQR) & $12.6(7.5-18.3)$ & $8.5(6.9-12.1)$ & 0.19 \\
\hline \multicolumn{4}{|l|}{ General Outcome: } \\
\hline Hospital mortality by day 28 & $12 / 17(70.6 \%)$ & $13 / 28(46.4 \%)$ & 0.11 \\
\hline Ventilator-free days to day 28, median (IQR) & $0(0-0)$ & $0(0-22)$ & 0.16 \\
\hline ICU-free days to day 28, median (IQR) & $0(0-0)$ & $0(0-20)$ & 0.14 \\
\hline \multicolumn{4}{|l|}{$\mathrm{IL}=$ Interleukin } \\
\hline \multicolumn{4}{|c|}{ APACHE = Acute Physiologic Assessment and Chronic Health Evaluation } \\
\hline \multicolumn{4}{|c|}{ RALE = Radiographic Assessment of Lung Edema } \\
\hline \multicolumn{4}{|l|}{ SOFA = Sequential Organ Failure Assessment } \\
\hline $\mathrm{ICU}=$ Intensive Care Unit & & & \\
\hline
\end{tabular}

\section{Discussion}

In this observational cohort of 50 patients that is representative of ARDS populations outside of clinical trials, the ventilatory ratio and the number of vasopressors required at baseline were strongly associated with mortality. Both of these clinical variables are easily obtained and could enhance bedside 
assessment of patient prognosis. In contrast to the oxygenation index, which did not improve model performance, the ventilatory ratio was the most discriminant respiratory variable for mortality. VR has previously been demonstrated to be associated with mortality in large cohorts of patients [5,25], but this is the first study to our knowledge to test the association between VR and mortality in a small observational cohort. These findings support the generalizability of VR as a prognostic variable in general populations of ARDS patients. Additionally, a three-variable parsimonious classifier model that included IL-8, protein C, and the lowest bicarbonate identified two sub-phenotypes of ARDS that have been previously identified predominantly in large RCTs, and those with a hyperinflammatory phenotype had substantially greater mortality.

Several measures of the severity of respiratory failure have been studied for their prognostic validity in ARDS. We tested $\mathrm{PaO}_{2} / \mathrm{FiO}_{2}$, oxygenation index, $\mathrm{VR}$, and the RALE score because of their frequent use in clinical and research settings and their established associations with ARDS outcomes [5, 18, 20,22, 26]. In previous work, a novel composite score that includes $\mathrm{PaO}_{2} / \mathrm{FiO}_{2}$, the RALE score, and VR had high discrimination for the need for ECMO or death from severe pulmonary dysfunction [27]. However, this score was derived from a single cohort without external validation and had poor discrimination for overall hospital mortality, so its generalizability remains unclear. In our study, the ventilatory ratio improved logistic regression models of 28-day mortality when combined with APACHE III, the most commonly used severity of illness score in ARDS, or with the number of vasopressors required at baseline. Additionally, a model that replaced the multi-component APACHE III with the number of vasopressors required at baseline performed similarly to the model with APACHE III. These findings are especially important given that this cohort was more representative of the general ARDS population than the subjects enrolled in clinical trials, as our subjects were critically ill with comorbidities and poor prognoses that often would lead to their exclusion from RCTs.

ARDS is a complex and heterogeneous syndrome that often involves both respiratory failure and multisystem organ dysfunction, leading to severe critical illness. Although the APACHE III score is a reliable measure of severity of illness, it is not designed to specifically measure the severity of lung injury or respiratory failure. Thus, we tested whether it would be valuable to supplement a measure of severity of illness with variables specific to respiratory compromise when modeling mortality in ARDS. Several indices of respiratory failure have been shown to have stronger independent associations with ARDS outcomes than the $\mathrm{PaO}_{2} / \mathrm{FiO}_{2}$ ratio $[24,28,29]$. Pulmonary dead space fraction $\left(\mathrm{V}_{\mathrm{D}} / \mathrm{V}_{\mathrm{T}}\right)$ is an independent predictor of mortality in ARDS [29]; however, estimation of dead space requires specialized equipment to measure the partial pressure of carbon dioxide $\left(\mathrm{PCO}_{2}\right)$ in mixed expired air. In this study, VR improved a model of 28-day mortality including APACHE III, which suggests that VR captures a domain of ARDS severity and lung injury that is not reflected by APACHE III alone. These findings are also consistent with the existing literature demonstrating that VR is independently associated with mortality even after adjusting for oxygenation, PEEP, and severity of illness with APACHE II [5]. Previous work has demonstrated the importance of identifying patients at risk of ARDS-attributable mortality [3], and our findings imply that VR can play a valuable role in identifying these high-risk patients. In addition, we 
found that a model including vasopressor number performed similarly to a model including the APACHE III score. Given its complexity and limited availability outside the research setting, the APACHE III score is rarely used in clinical practice, and these results indicate that vasopressor number may represent similar prognostic information. Additionally, likelihood ratio testing indicates that the performance of a model with vasopressor number, like the APACHE III score, is augmented when VR is added.

VR alone was also associated with mortality, while pulmonary dead space fraction was not. This can likely be attributed to the fact that VR provides information about both pulmonary dead space and metabolic derangements, including carbon dioxide excretion and production [17]. Additionally, when VR was dichotomized into "high VR" ( $\geq 2)$ and "low VR," (<2) mortality was significantly greater among patients with high VR. VR had high mortality discrimination even in a modest cohort of patients and is easily obtained without the use of specialized equipment. Thus, VR may be a reliable and underappreciated tool for prognostication even outside of large RCTs.

Two ARDS phenotypes, termed hyperinflammatory and hypoinflammatory, have been accurately and consistently identified in numerous cohorts from randomized controlled trials of ARDS. Pending rapid biomarker quantification, parsimonious models offer a simple and unique method for prognostic enrichment. Interpreting parsimonious classifier models has largely been limited to the clinical trial populations in which they were derived and validated, although there is a growing body of evidence that these subphenotypes may be generalizable to unselected populations of ARDS [30]. The present study demonstrates a substantial trend (although not statistically significant) towards greater mortality in the hyperinflammatory phenotype, suggesting that these classifier models may be more widely applicable.

Although the sample size of this study potentially limits its generalizability, we deliberately tested our hypotheses in a modest-sized cohort in order to elucidate which physiologic and biologic factors were most relevant to a cohort of ARDS patients representative of clinical practice. This study had very few exclusion criteria. As a result and in contrast to many randomized controlled trials, our cohort included severely ill patients with multiple comorbidities. Chronic respiratory failure, chronic liver disease, previous bone marrow transplantation, and prior lung transplantation are all medical problems that were

represented in our cohort but have been exclusion criteria in many of the landmark ARDS studies [31-33]. As was observed in the LUNG-SAFE study [34], patients in observational cohorts are often more systemically ill and have higher mortality rates. Observational studies such as this one are representative of clinical practice and have a crucial role in the generalizability of ARDS research.

\section{Conclusions}

The results of this study underscore that ventilatory ratio is a valuable tool for mortality risk assessment and captures a domain of ARDS severity that is not reflected by general severity of illness indicators. Although ventilatory ratio improved a model of 28-day mortality when added to a severity of illness score, it also performed well on its own at discriminating between those who lived and those who died. This severely ill cohort is representative of ARDS in clinical practice, more so than the carefully selected 
populations that generally meet all criteria for enrollment in clinical trials. Thus, ventilatory ratio, a respiratory variable that is convenient to calculate using information already collected in critically ill patients, may be valuable for both clinical trials that aim to enrich for the patients with the greatest chance of mortality and for risk assessment and shared decision making in the clinical setting.

\section{List Of Abbreviations}

Ang-2: Angiopoietin 2

APACHE III: Acute physiology and chronic health evaluation III

ARDS: Acute respiratory distress syndrome

AUROC: Area under the receiver operating curve

IL: Interleukin

Ol: Oxygenation Index

$\mathrm{PaO}_{2} / \mathrm{FiO}_{2}$ : Arterial oxygen tension/fraction of inspired oxygen

$\mathrm{PCO}_{2}$ : Partial pressure of carbon dioxide

PEEP: Positive end-expiratory pressure

RAGE: Receptor for advanced glycation end-products

RALE: Radiographic assessment of lung edema

RCT: Randomized controlled trial

sTNFR-1: Soluble tumor necrosis factor receptor-1

$V_{D} / V_{T}$ : Dead space fraction

VFD: Ventilator-free days to day 28

VR: Ventilatory ratio

\section{Declarations}

Ethical approval and consent: This study was approved by the UCSF Institutional Review Board. Informed consent for participation was obtained for all participants. If the patient was unable to provide consent, consent was obtained from a surrogate. 
Consent for publication: Full consent from all participants was obtained including consent for publication of data.

Availability of Data and Materials: Primary data is available upon request from the corresponding author.

\section{Competing Interests:}

Michael Matthay receives grant support from Roche-Genentech for ARDS observational studies and consulting income from Citius Pharmaceuticals, Johnson and Johnson, Gilead Pharmaceuticals, Plant Therapeutics, and Novartis pharmaceuticals outside of the present work. Carolyn Calfee served as a consultant for Bayer, CSL Behring, Gen1e Life Sciences, Prometic, Roche/Genentech, Quark, and Vasomune and received research support from Bayer, GlaxoSmithKline, NIH, Roche/Genentech, and Quantum Leap Healthcare Collaborative.

All other authors declare no competing interests.

Funding. This study was funded by grants from the National Institutes of Health: 5TL1TR001871-05 (ERS), R35 HL140026 (CSC), and R01 HL134828 (MAM). KDW has received grant support from NIH 5T32GM008440-24. This research was also supported by a grant from Bayer Pharmaceuticals, which had no role in the design of the study or interpretation of results.

\section{Author contributions:}

Emily R. Siegel: This author helped acquire, analyze, and interpret the data; draft the manuscript; provide critical revisions and approve the final manuscript; and agreed to be accountable for all aspects of the work.

Hanjing Zhuo: This author helped analyze and interpret the data, provide critical revisions, and approve the final manuscript, and agreed to be accountable for all aspects of the work.

Pratik Sinha: This author helped interpret the data, provide critical revisions, and approve the final manuscript, and agreed to be accountable for all aspects of the work.

Alexander Papolos: This author helped conceive and design the study, acquire and interpret the data, obtained informed consent, provide critical revisions, and approve the final manuscript, and agreed to be accountable for all aspects of the work.

Siyuan A. Ni: This author helped acquire the data, obtain informed consent, provide critical revisions, and approve the final manuscript, and agreed to be accountable for all aspects of the work.

Kathryn Vessel: This author helped acquire the data, provide critical revisions, and approve the final manuscript, and agreed to be accountable for all aspects of the work. 
Annika Belzer: This author helped acquire the data, provide critical revisions, and approve the final manuscript, and agreed to be accountable for all aspects of the work.

Emily Minus: This author helped acquire the data, provide critical revisions, and approve the final manuscript, and agreed to be accountable for all aspects of the work.

Michael A. Matthay and Carolyn S. Calfee: These authors conceived and designed the study, interpreted the data, provide critical revisions, and approve the final manuscript, and agreed to be accountable for all aspects of the work.

Katherine D. Wick: This author helped analyze and interpret the data, provide critical revisions, and approve the final manuscript, and agreed to be accountable for all aspects of the work.

Acknowledgements. We thank the patients and families for their consent and participation in this study, without whom this research would not have been possible.

\section{References}

1. Ware LB, Matthay MA, Mebazaa A: Designing an ARDS trial for 2020 and beyond: focus on enrichment strategies. Intensive Care Med 2020, 46(12):2153-2156.

2. Matthay MA, Arabi YM, Siegel ER, Ware LB, Bos LDJ, Sinha P, Beitler JR, Wick KD, Curley MAQ, Constantin JM et al: Phenotypes and personalized medicine in the acute respiratory distress syndrome. Intensive Care Med 2020, 46(12):2136-2152.

3. Auriemma CL, Zhuo H, Delucchi K, Deiss T, Liu T, Jauregui A, Ke S, Vessel K, Lippi M, Seeley E et al: Acute respiratory distress syndrome-attributable mortality in critically ill patients with sepsis. Intensive Care Med 2020, 46(6):1222-1231.

4. Knaus WA, Wagner DP, Draper EA, Zimmerman JE, Bergner M, Bastos PG, Sirio CA, Murphy DJ, Lotring T, Damiano A et al: The APACHE III prognostic system. Risk prediction of hospital mortality for critically ill hospitalized adults. Chest 1991, 100(6):1619-1636.

5. Sinha P, Calfee CS, Beitler JR, Soni N, Ho K, Matthay MA, Kallet RH: Physiologic Analysis and Clinical Performance of the Ventilatory Ratio in Acute Respiratory Distress Syndrome. Am J Respir Crit Care Med 2019, 199(3):333-341.

6. Flori H, Sapru A, Quasney MW, Gildengorin G, Curley MAQ, Matthay MA, Dahmer MK, Bali, Restore Study Investigators PALI, Sepsis Investigators N: A prospective investigation of interleukin-8 levels in pediatric acute respiratory failure and acute respiratory distress syndrome. Crit Care 2019, 23(1):128.

7. Anderson BJ, Calfee CS, Liu KD, Reilly JP, Kangelaris KN, Shashaty MGS, Lazaar AL, Bayliffe Al, Gallop RJ, Miano TA et al: Plasma sTNFR1 and IL8 for prognostic enrichment in sepsis trials: a prospective cohort study. Crit Care 2019, 23(1):400.

8. Matthay MA, Ware LB: Plasma protein $\mathrm{C}$ levels in patients with acute lung injury: prognostic significance. Crit Care Med 2004, 32(5 Suppl):S229-232. 
9. Sinha P, Delucchi KL, McAuley DF, O'Kane CM, Matthay MA, Calfee CS: Development and validation of parsimonious algorithms to classify acute respiratory distress syndrome phenotypes: a secondary analysis of randomised controlled trials. Lancet Respir Med 2020, 8(3):247-257.

10. Calfee CS, Delucchi KL, Sinha P, Matthay MA, Hackett J, Shankar-Hari M, McDowell C, Laffey JG, O'Kane CM, McAuley DF et al: Acute respiratory distress syndrome subphenotypes and differential response to simvastatin: secondary analysis of a randomised controlled trial. Lancet Respir Med 2018, 6(9):691-698.

11. Delucchi K, Famous KR, Ware LB, Parsons PE, Thompson BT, Calfee CS, Network A: Stability of ARDS subphenotypes over time in two randomised controlled trials. Thorax 2018, 73(5):439-445.

12. Sinha P, Delucchi KL, Thompson BT, McAuley DF, Matthay MA, Calfee CS, Network NA: Latent class analysis of ARDS subphenotypes: a secondary analysis of the statins for acutely injured lungs from sepsis (SAILS) study. Intensive Care Med 2018, 44(11):1859-1869.

13. Famous KR, Delucchi K, Ware LB, Kangelaris KN, Liu KD, Thompson BT, Calfee CS, Network A: Acute Respiratory Distress Syndrome Subphenotypes Respond Differently to Randomized Fluid Management Strategy. Am J Respir Crit Care Med 2017, 195(3):331-338.

14. Pais FM, Sinha P, Liu KD, Matthay MA: Influence of Clinical Factors and Exclusion Criteria on Mortality in ARDS Observational Studies and Randomized Controlled Trials. Respir Care 2018, 63(8):1060-1069.

15. Force ADT, Ranieri VM, Rubenfeld GD, Thompson BT, Ferguson ND, Caldwell E, Fan E, Camporota L, Slutsky AS: Acute respiratory distress syndrome: the Berlin Definition. JAMA 2012, 307(23):25262533.

16. Cepkova M, Kapur V, Ren X, Quinn T, Zhuo H, Foster E, Liu KD, Matthay MA: Pulmonary dead space fraction and pulmonary artery systolic pressure as early predictors of clinical outcome in acute lung injury. Chest 2007, 132(3):836-842.

17. Sinha P, Sanders RD, Soni N, Vukoja MK, Gajic O: Acute respiratory distress syndrome: the prognostic value of ventilatory ratio-a simple bedside tool to monitor ventilatory efficiency. Am J Respir Crit Care Med 2013, 187(10):1150-1153.

18. Warren MA, Zhao Z, Koyama T, Bastarache JA, Shaver CM, Semler MW, Rice TW, Matthay MA, Calfee CS, Ware LB: Severity scoring of lung oedema on the chest radiograph is associated with clinical outcomes in ARDS. Thorax 2018, 73(9):840-846.

19. DeLong ER, DeLong DM, Clarke-Pearson DL: Comparing the areas under two or more correlated receiver operating characteristic curves: a nonparametric approach. Biometrics 1988, 44(3):837-845.

20. Monchi M, Bellenfant F, Cariou A, Joly LM, Thebert D, Laurent I, Dhainaut JF, Brunet F: Early predictive factors of survival in the acute respiratory distress syndrome. A multivariate analysis. Am J Respir Crit Care Med 1998, 158(4):1076-1081.

21. Balzer F, Menk M, Ziegler J, Pille C, Wernecke KD, Spies C, Schmidt M, Weber-Carstens S, Deja M: Predictors of survival in critically ill patients with acute respiratory distress syndrome (ARDS): an observational study. BMC Anesthesio/ 2016, 16(1):108. 
22. Gajic O, Afessa B, Thompson BT, Frutos-Vivar F, Malinchoc M, Rubenfeld GD, Esteban A, Anzueto A, Hubmayr RD, Second International Study of Mechanical V et al: Prediction of death and prolonged mechanical ventilation in acute lung injury. Crit Care 2007, 11(3):R53.

23. Ware LB: Prognostic determinants of acute respiratory distress syndrome in adults: impact on clinical trial design. Crit Care Med 2005, 33(3 Suppl):S217-222.

24. Seeley E, McAuley DF, Eisner M, Miletin M, Matthay MA, Kallet RH: Predictors of mortality in acute lung injury during the era of lung protective ventilation. Thorax 2008, 63(11):994-998.

25. Morales-Quinteros L, Schultz MJ, Bringue J, Calfee CS, Camprubi M, Cremer OL, Horn J, van der Poll $\mathrm{T}$, Sinha $\mathrm{P}$, Artigas A et al: Estimated dead space fraction and the ventilatory ratio are associated with mortality in early ARDS. Ann Intensive Care 2019, 9(1):128.

26. Ferguson ND, Fan E, Camporota L, Antonelli M, Anzueto A, Beale R, Brochard L, Brower R, Esteban A, Gattinoni $L$ et al: The Berlin definition of ARDS: an expanded rationale, justification, and supplementary material. Intensive Care Med 2012, 38(10):1573-1582.

27. Sedhai YR, Yuan M, Ketcham SW, Co I, Claar DD, McSparron JI, Prescott HC, Sjoding MW: Validating Measures of Disease Severity in Acute Respiratory Distress Syndrome. Ann Am Thorac Soc 2020.

28. DesPrez K, McNeil JB, Wang C, Bastarache JA, Shaver CM, Ware LB: Oxygenation Saturation Index Predicts Clinical Outcomes in ARDS. Chest 2017, 152(6):1151-1158.

29. Nuckton TJ, Alonso JA, Kallet RH, Daniel BM, Pittet JF, Eisner MD, Matthay MA: Pulmonary deadspace fraction as a risk factor for death in the acute respiratory distress syndrome. $N$ Engl $\mathrm{J}$ Med 2002, 346(17):1281-1286.

30. Sinha P, Delucchi KL, Chen Y, Zhuo H, Abbott J, Wang C, Wickersham N, McNeil JB, Jauregui A, Ke S et al: Latent class analysis-derived subphenotypes are generalisable to observational cohorts of acute respiratory distress syndrome: a prospective study. Thorax 2021.

31. National Heart L, Blood Institute PCTN, Moss M, Huang DT, Brower RG, Ferguson ND, Ginde AA, Gong MN, Grissom CK, Gundel S et al: Early Neuromuscular Blockade in the Acute Respiratory Distress Syndrome. N Engl J Med 2019, 380(21):1997-2008.

32. Acute Respiratory Distress Syndrome N, Brower RG, Matthay MA, Morris A, Schoenfeld D, Thompson BT, Wheeler A: Ventilation with lower tidal volumes as compared with traditional tidal volumes for acute lung injury and the acute respiratory distress syndrome. N Engl J Med 2000, 342(18):13011308.

33. Guerin C, Reignier J, Richard JC, Beuret P, Gacouin A, Boulain T, Mercier E, Badet M, Mercat A, Baudin $O$ et al: Prone positioning in severe acute respiratory distress syndrome. N Engl J Med 2013, 368(23):2159-2168.

34. Bellani G, Laffey JG, Pham T, Fan E, Brochard L, Esteban A, Gattinoni L, van Haren F, Larsson A, McAuley DF et al: Epidemiology, Patterns of Care, and Mortality for Patients With Acute Respiratory Distress Syndrome in Intensive Care Units in 50 Countries. JAMA 2016, 315(8):788-800.

\section{Figures}


322 Patients endotracheally intubated and met Berlin criteria for ARDS

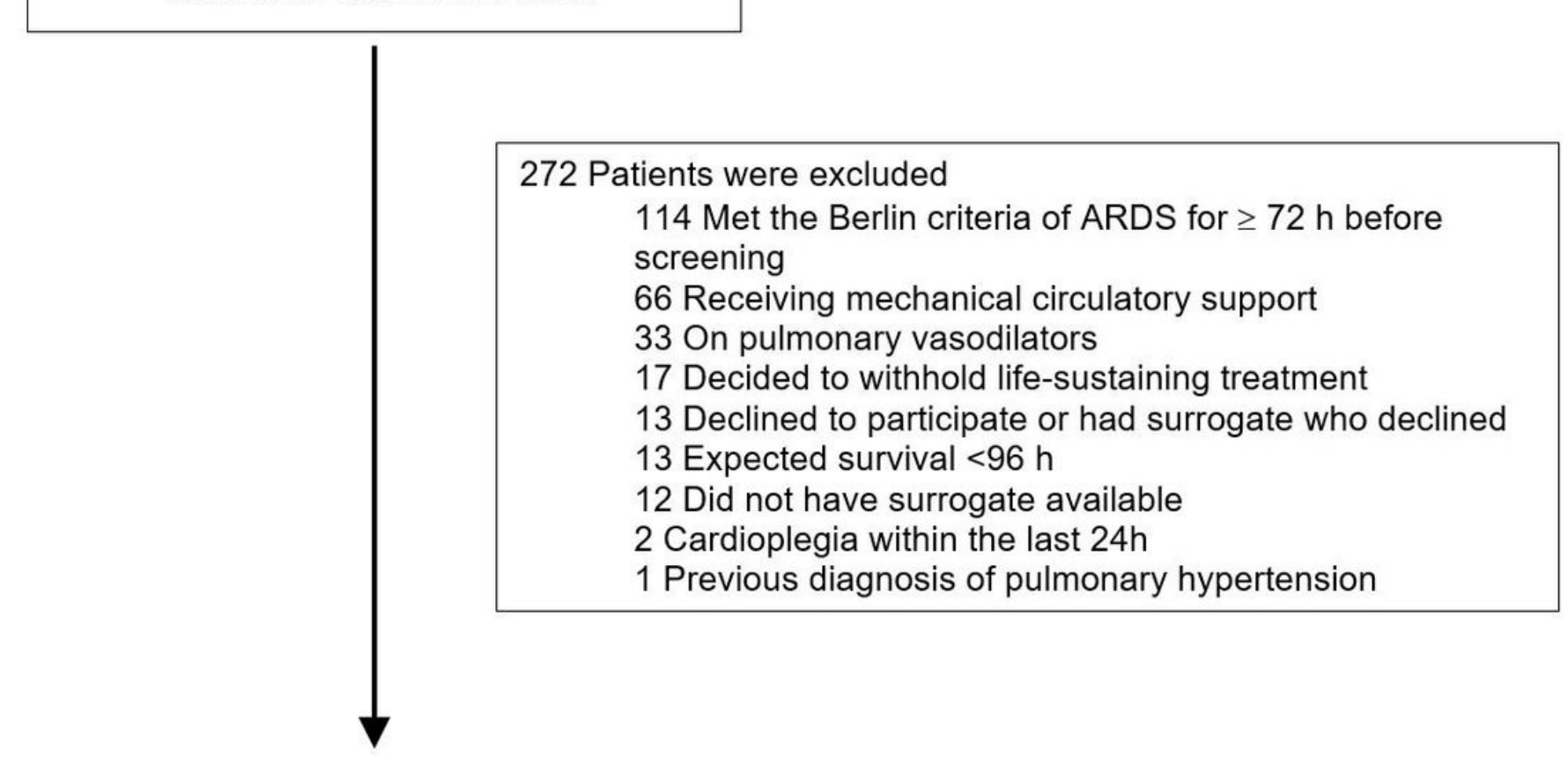

50 patients included in final analysis

Figure 1

Flowchart of patient screening and enrollment. 


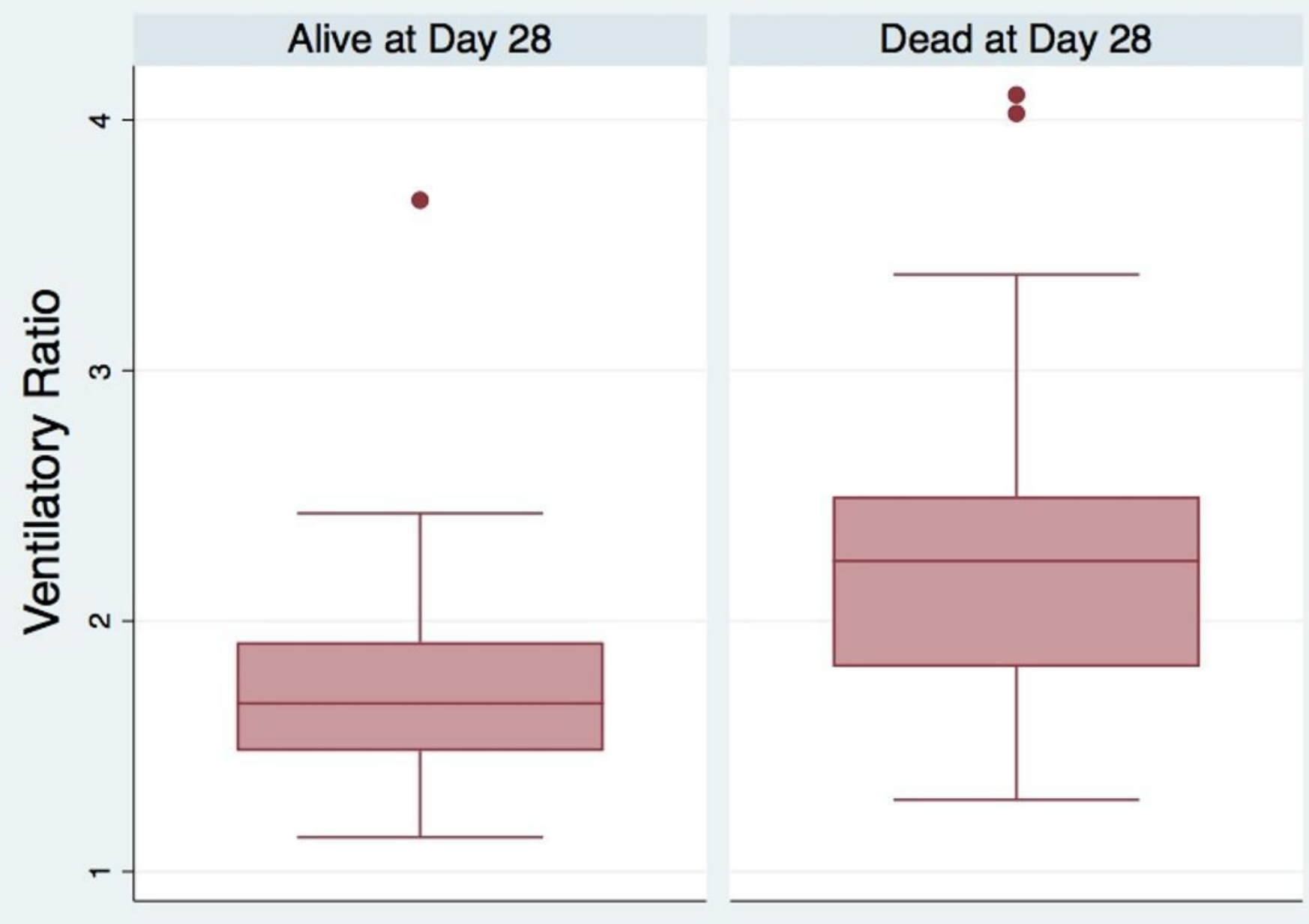

Figure 2

Box plot of ventilatory ratio dichotomized by Alive $(n=22)$ vs. Dead $(n=28)$ at Day 28 . Ventilatory ratio was significantly higher among non-survivors, $\mathrm{p}=0.01$ by Wilcoxon Rank Sum. 